\title{
ANALYSIS OF CORROSION PRODUCTS FROM WW2 CONCRETE BUNKERS IN CZECHIA
}

\author{
Michal NÝVlT*, JiŘí PAZDERKA \\ Czech Technical University in Prague, Faulty of Civil Engineering, Thákurova 7/2077, 16629 Prague, Czech \\ Republic \\ * corresponding author: michal.nyvlt@fsv.cvut.cz
}

\begin{abstract}
The paper deals with analysis of corrosion products from historic concrete bunkers which were built in the 1930's. Most of these objects evince numerous failures due to water penetration into the concrete structures. Two heavy bunkers became the target of research which was focused on chemical and biological analysis of corrosion products from concrete structures. The results showed that concrete used for two analyzed fortifications successfully resisted the long-lasting effects of chemical corrosion as well as bio-corrosion (this corrosion causes only aesthetic defects).
\end{abstract}

KEYWORDS: Corrosion, concrete, bunker, WW2, failures.

\section{INTRODUCTION}

Just before WW2, in the 1930's, a lot of concrete fortifications was built in the Czechoslovakia (Czechia today). After 80 years, most of these military objects evince numerous failures due to water penetration into the concrete structures. The major part of these objects consists of light infantry bunkers (type 36 and type 37) but along the Nord border of Czechia, there were constructed 260 heavy bunkers following the example of the French Maginot line. They were large two floored buildings with strengthening ballistic protection made of heavily reinforced concrete. Two of these objects became the target for subsequent research which was focused on analysis of corrosion products from concrete structures.

\section{EXPERIMENTAL PROGRAM}

For the purpose of the work, 10 samples were taken. 5 for salinity and 5 for localization of mold. The probes were carried out using a disinfected spatula by scraping off the surface of the concrete walls. The sampling sites were selected to map the chemical and biological damage of two object heavy concrete fortifications. These are bunkers No. T-S-20 and No. T-S-19 (figure 1, figure 21.

\section{MAterials AND METHOD}

A total of 5 samples of concrete from two heavy fortification buildings were tested. Most inorganic compounds are water-soluble due to their ionic structure. It is possible to detect the contents of these by using an aqueous solution. The salinity evaluation was started by weighing $2 \mathrm{~g}$ of the crushed sample into the Erlenmeyer flasks. After addition of $100 \mathrm{ml}$ of distilled water, the flasks were transferred to an electric cooker, where they heated to boiling point and then subjected to ultrasound. This step resulted in the fragmentation of individual parts (figure 3 ).
The prepared solution was sedimented for 24 hours. The portion of the sample without haze and sediment was removed using a pipette. The prepared samples were then placed in clean glass caps and prepared for further examination (figure 4).

The Merck - UV-VIS photometer Spectrogant Pharo 300 was used to evaluate all methods.

\subsection{PH MEASURING}

The first step of experiment was made an indicative measurement of $\mathrm{pH}$ using analytical test strips. The reason for this was to determine the range of measurements for further use. In case of too high concentrations it would not be possible to obtain the results from the photometer. For samples 2 and 5, it was necessary to dilute with 1:10 distilled water.

Using a pipette, $1 \mathrm{ml}$ of pre-prepared sample and 3 drops of universal indicators were added to the tube. After shaking and terminating the reaction, the sample changed color. On the basis of the colorimetric reaction, the approximate $\mathrm{pH}$ was determined (figure 5 figure 6).

\subsection{Measurement of Chloride salts $\mathrm{Cl}^{-}$}

Chloride ions react with mercury thiocyanate to form slightly dissociated mercuric chloride [1]. Loose thiocyanate is reacted with ferric ions in a red ferric thiocyanate which was determined photometrically [1].

$5 \mathrm{ml}$ of the treated sample was measured using a pipette. Additionally, $2.5 \mathrm{ml}$ of $\mathrm{Cl}^{-1}$ reagent and $0.5 \mathrm{ml}$ of $\mathrm{Cl}^{-2}$ reagent were added. After thorough shaking and settling of the sample ( 1 minute), the sample was evaluated. The evaluation was carried out in the Spectrogant Pharo 300 UV-VIS photometer.

\subsection{Measurement of Ammonia $\mathrm{NH}_{4}^{+}$}

Ammoniacal nitrogen $\left(\mathrm{NH}_{4}-\mathrm{N}\right)$ occurs partly in the form of ammonium ions and partly as ammonia [1]. 


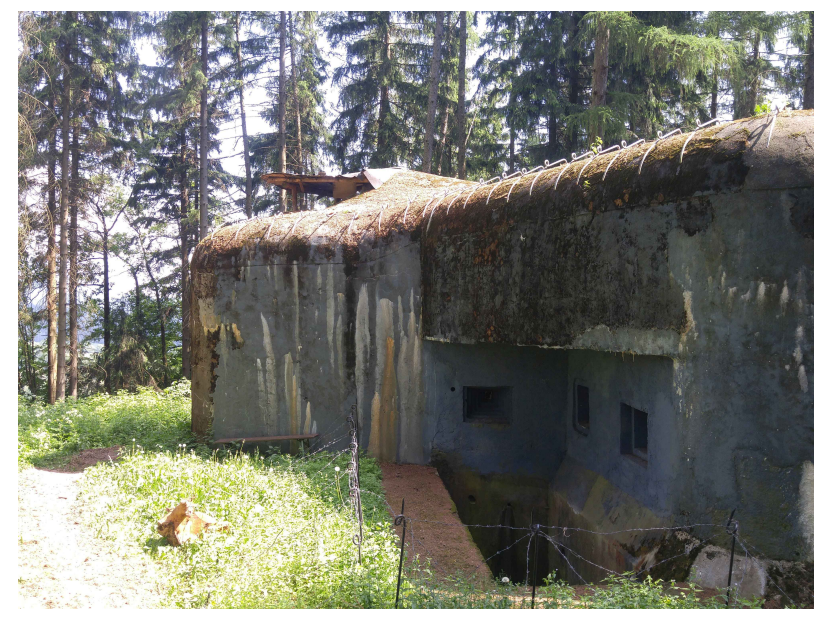

Figure 1. Sampling site: bunker No. T-S-20.

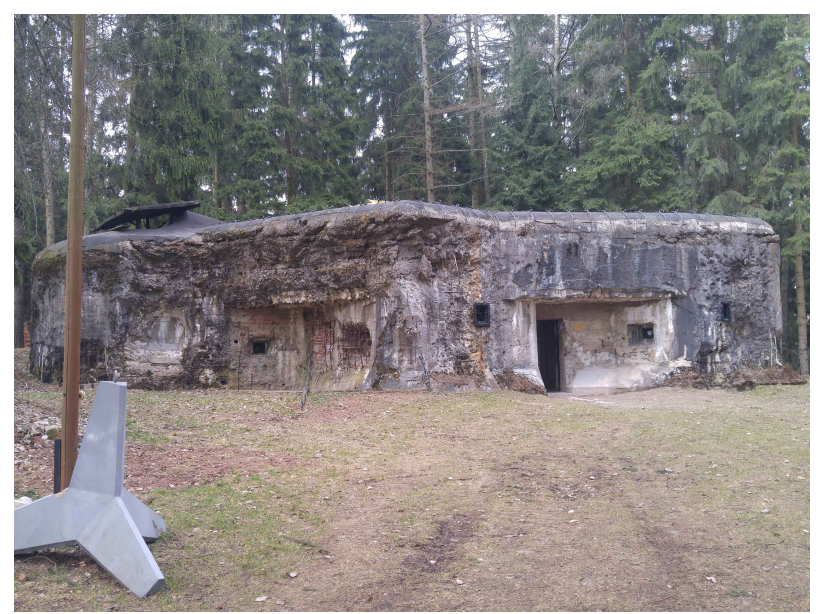

Figure 2. Sampling site: bunker No. T-S-19.

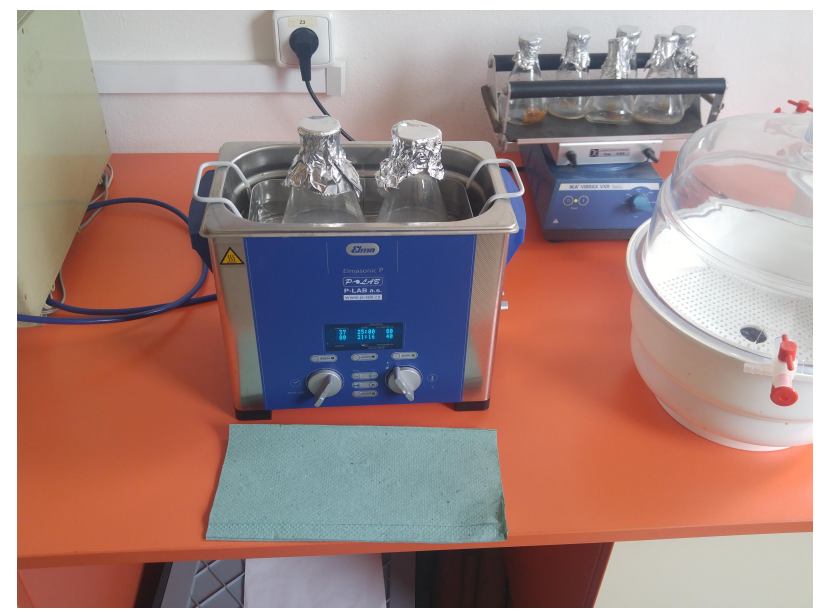

Figure 3. The samples are exposed to ultrasound.

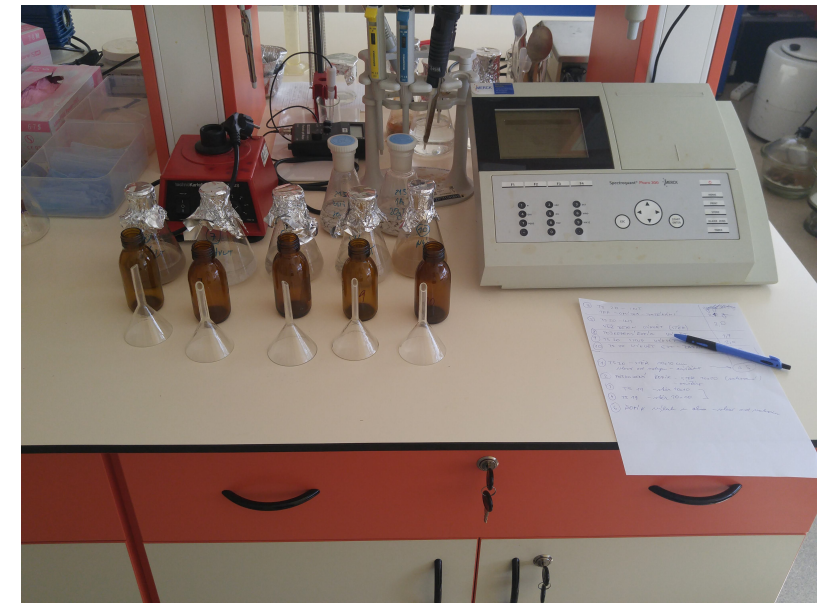

FigURE 4. Inserting the samples into clean glass cap.

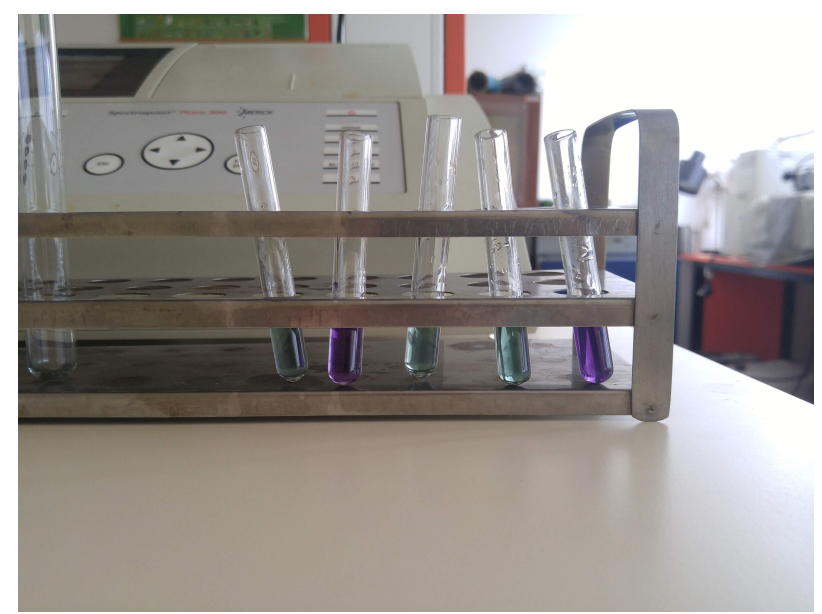

Figure 5. Samples with added pH indicator.

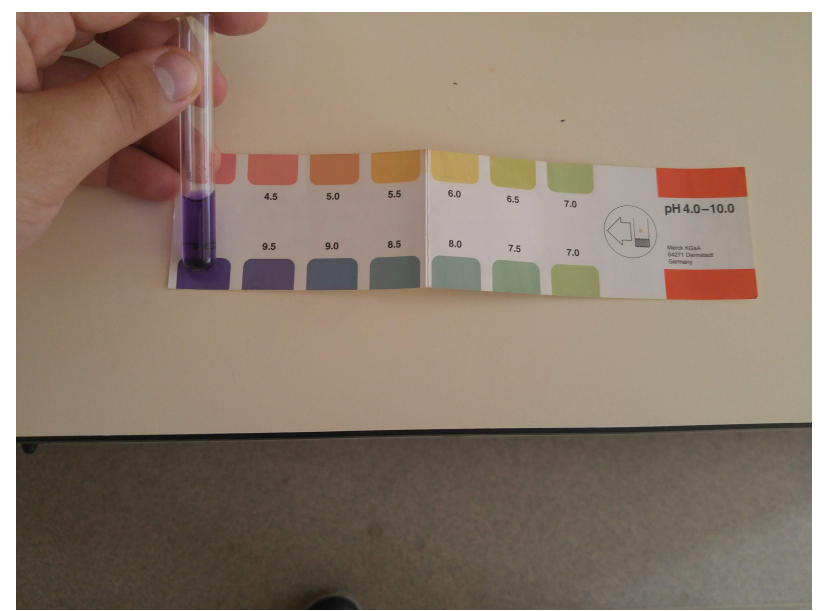

Figure 6. Colorimetric evaluation of $\mathrm{pH}$ by color and scale. 
Among these forms there is a $\mathrm{pH}$-dependent equilibrium [1]. In strongly alkaline solutions, $\mathrm{NH}_{4}-\mathrm{N}$ is present almost exclusively as ammonia which reacts with hypochlorites to form monochloramine [1]. Monochloramine is further reacted with thymol to give blue indophenol, the concentration of which is then determined photometrically 1 .

A reagent is added to the $5 \mathrm{ml}$ treated sample. $0.6 \mathrm{ml}$ of $\mathrm{NH}_{4}-1$ reagent and $0.06 \mathrm{ml}$ of $\mathrm{NH}_{4}-2$ reagent are used. After shaking, the tube was left for 5 minutes and then 4 drops of $\mathrm{NH}_{4}-3$ were added. The evaluation was carried out in the Spectrogant Pharo 300 UV-VIS photometer.

\subsection{Measurement of Sulphate SAlts $\mathrm{SO}_{4}^{-2}$}

Sodium ions react with barium iodate, iodine ions are released [1]. They oxidize to form a brown-red compound that is photometrically determined [1].

In this assay method, $2.5 \mathrm{ml}$ of the conditioned sample was metered into the prepared tubes. Experimental $\mathrm{pH}$ measurements for samples 2 and 5 found to be $\mathrm{pH}$ higher than 10 . For this reason, these samples were diluted 1:10 with distilled water. Subsequently, 2 drops of $\mathrm{SO}_{4}^{-1}$ reagent and $0.06 \mathrm{ml}$ of $\mathrm{SO}_{4}^{-2}$ reagent were added to every tubes with samples. After shaking, the tubes were heated to $40{ }^{\circ} \mathrm{C}$ for about 5 minutes. Then, $2.5 \mathrm{ml}$ of $\mathrm{SO}_{4}^{-3}$ reagent was added and a sample was filtered through the filter paper into an empty tube. Four drops of $\mathrm{SO}_{4}^{-4}$ were added to the filtered solution followed by further heating to $40^{\circ} \mathrm{C}$. After 7 minutes, the sample could be evaluated in a Spectrogant Pharo 300 UV-VIS photometer.

\subsection{Measurement of nitrate salts $\mathrm{NO}_{3}^{-}$}

In concentrated sulfuric acid, the nitrate ions react with the benzoic acid derivative to form the red colored nitro compound whose concentrations are determined photometrically [1].

Prior to the start of the test, a solution of $0.06 \mathrm{ml}$ of $\mathrm{NO}_{3}^{-1}$ reagent and $\mathrm{ml}$ of $\mathrm{NO}_{3}^{-2}$ reagent was required to be prepared. After shaking the vials and completely dissolving the reagents, add $1.5 \mathrm{ml}$ of the conditioned sample. Subsequently, the samples were sedimented. sedimentation samples could be evaluated in a Spectrogant Pharo 300 UV-VIS photometer.

\subsection{Microbiology AND MOLD}

Within the experiment, it was also interesting to deal with biological damage to objects. Biological damage can be investigated in several ways, for the purpose of the work, it was most appropriate to examine the samples using a microscope.

Sterile instruments were picked up in trace amounts of samples and seeded into the broth with agar solution in prepared Petri dishes.

Agar preparation was carried out in $200 \mathrm{ml}$ Erlenmeyer flasks. For $200 \mathrm{ml}$ of solution it is necessary to add $3.8 \mathrm{~g}$ of agar and $5 \mathrm{~g}$ malt broth. All ingredients

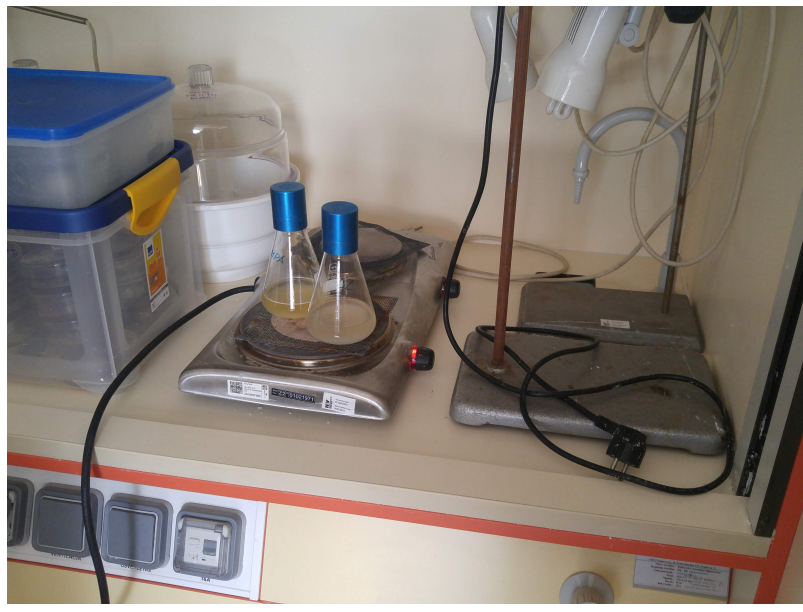

Figure 7. Heating the agar solution on an electric cooker.

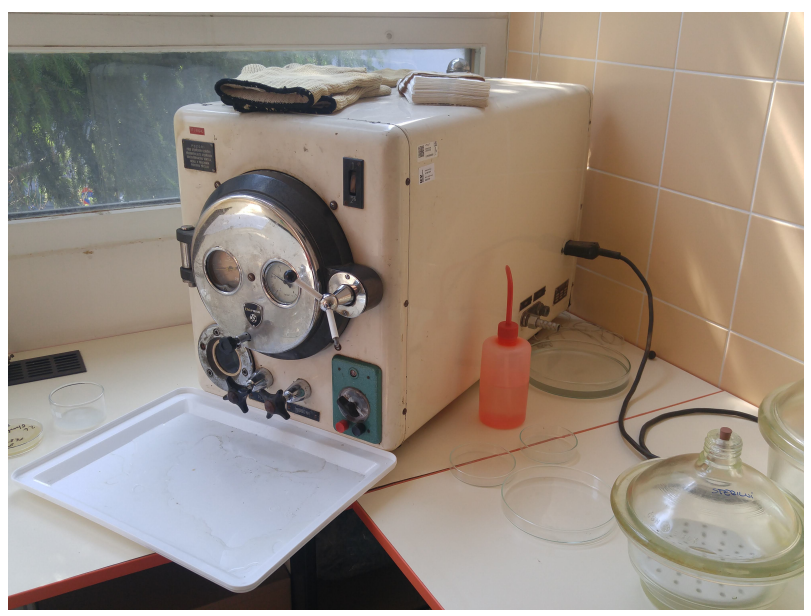

FiguRE 8. Used sterilization device.

were mixed and heated with $200 \mathrm{ml}$ of distilled water (figure 7). The prepared agar solution was sterilized in an autoclave for exactly 20 minutes at $120^{\circ} \mathrm{C}$ and pressure $100 \mathrm{kPa}$ (Figure 8). To the clean, sterile Petri dishes, about $3 \mathrm{~mm}$ thick solution was poured and quickly covered to prevent contamination from outside. It is then possible to transfer specimens to the solid solution. Samples were cultured in a thermostat at $22 \pm 3^{\circ} \mathrm{C}$ for 2 weeks. The mold appeared in all 5 samples (Figure 9 Figure 10.

The mold sample was transferred to the glass slide. Then it was folded over the glass cover and viewed under a microscope with magnification of $\times 40$ and $\times 100$ (Figure 11). After consultation with the microbiologist, 6 species of mold were identified and identified. Alternaria alternata, Fusarium culmorum, Trichoderma viride, Cladosporium herbarum, Phoma eupyrena and Penicillium (Figure 12 - Figure 14.

All species found are naturally occurring molds that normally would not have a significant impact on the durability of the concrete structures in question. 


\begin{tabular}{|c|c|c|c|c|c|c|}
\hline \multirow{3}{*}{$\begin{array}{l}\text { Degree of salvation } \\
\text { of masonry }\end{array}$} & \multicolumn{6}{|c|}{ Salt content in $\mathrm{mg} / \mathrm{g}$ and percentage by weight } \\
\hline & \multicolumn{2}{|c|}{ Chloride content } & \multicolumn{2}{|c|}{ Nitrate content } & \multicolumn{2}{|c|}{ Sulphate content } \\
\hline & {$[\mathrm{mg} / \mathrm{g}]$} & [\% by weight] & {$[\mathrm{mg} / \mathrm{g}]$} & [\% by weight] & {$[\mathrm{mg} / \mathrm{g}]$} & [\% by weight] \\
\hline Low values & $<0.75$ & $<0.075$ & $<1.0$ & $<0.1$ & $<5.0$ & $<0.5$ \\
\hline Increased values & $0.75-2.0$ & $0.075-0.20$ & $1.0-2.5$ & $0.1-0.25$ & $5.0-20$ & $0.5-2.0$ \\
\hline High values & $2.0-5.0$ & $0.20-0.50$ & $2.5-5.0$ & $0.25-0.50$ & $20-50$ & $2.0-5.0$ \\
\hline Very high values & $>5.0$ & $>0.50$ & $>5.0$ & $>0.50$ & $>50$ & $>5.0$ \\
\hline
\end{tabular}

TABLE 1. Table from the Czech technical standard ČSN P 730610.

\begin{tabular}{ccccccc}
\hline $\begin{array}{c}\text { Sample } \\
\text { identification } \\
\mathrm{g}]\end{array}$ & $\begin{array}{c}\text { Weight } \\
{[-]}\end{array}$ & $\begin{array}{c}\mathrm{pH} \\
{[\mathrm{mg} / \mathrm{g}]}\end{array}$ & $\begin{array}{c}\text { Chloride } \\
\text { content } \\
{[\mathrm{mg} / \mathrm{g}]}\end{array}$ & $\begin{array}{c}\text { Ammonia } \\
\text { content } \\
{[\mathrm{mg} / \mathrm{g}]}\end{array}$ & $\begin{array}{c}\text { Nitrate } \\
\text { content } \\
{[\mathrm{mg} / \mathrm{g}]}\end{array}$ & $\begin{array}{c}\text { Sulphate } \\
\text { content }\end{array}$ \\
\hline 1 & 2.1 & 8.5 & $<0.53$ & 0 & 0.48 & 7.1 \\
2 & 2.0 & 10 & 0 & 0 & 0.42 & $30^{1}$ \\
3 & 1.9 & 8.5 & $<0.48$ & 0 & 1.178 & 6.7 \\
4 & 2.0 & 8.5 & 0 & 0 & 0.44 & 7 \\
5 & 2.0 & 10 & $<0.42$ & 0 & 0.8 & $35.4^{1}$ \\
\hline
\end{tabular}

${ }^{1}$ Experimental $\mathrm{pH}$ measurements for samples 2 and 5 found to be $\mathrm{pH}$ higher than 10 . For this reason, these samples were diluted 1:10 with distilled water.

TABLE 2. Salinity measurement.

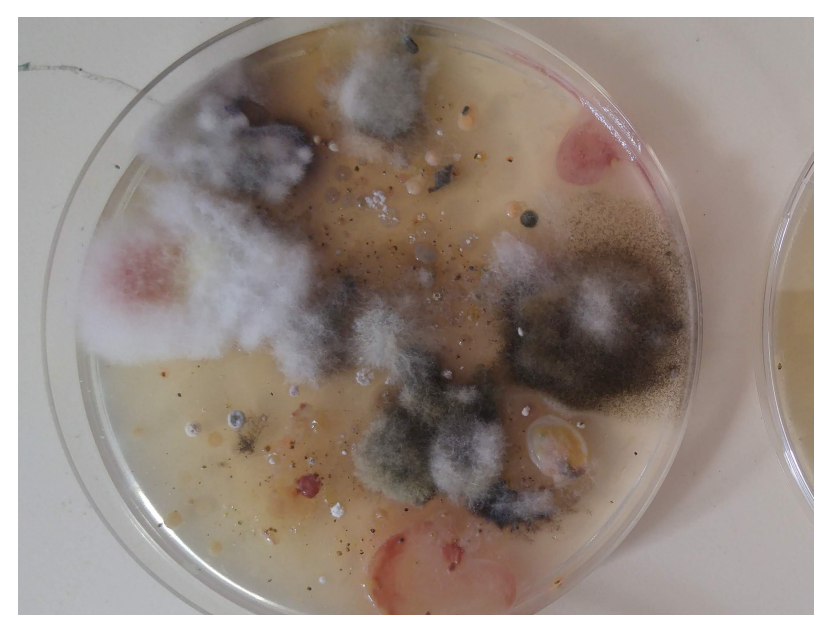

Figure 9. Mold on sample number 1.

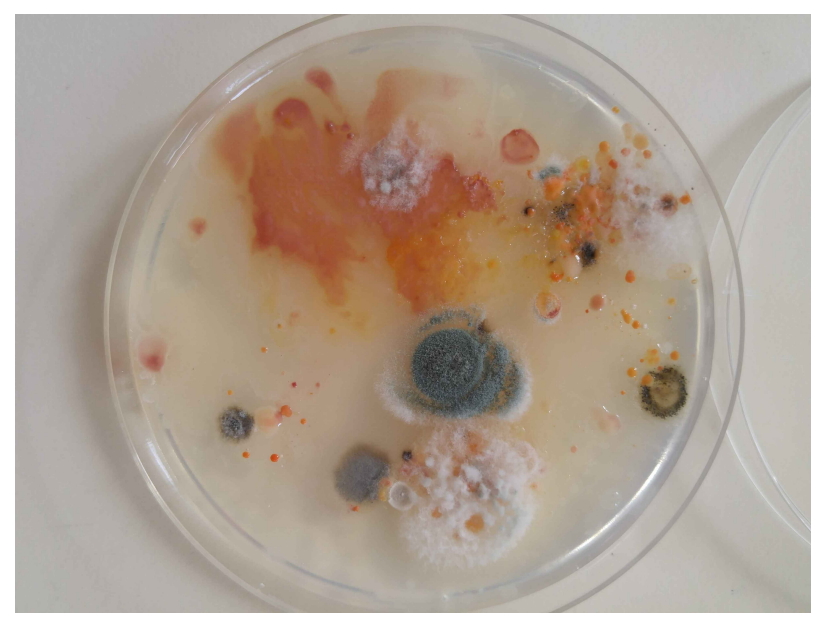

FiguRE 10. Mold on sample number 2.

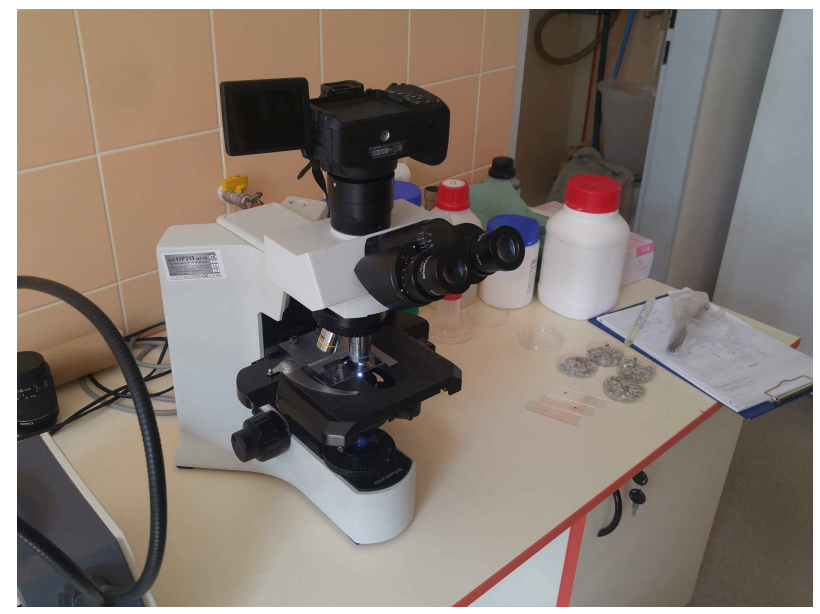

Figure 11. Observation of mold samples by microscope.

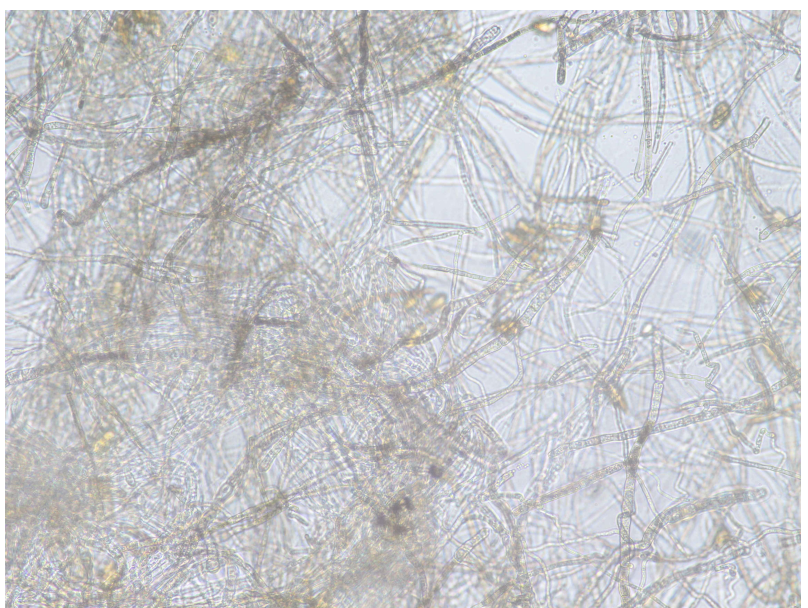

Figure 12. Alternaria alternata. 


\begin{tabular}{ccccc}
\hline $\begin{array}{c}\text { Sample } \\
\text { identification }\end{array}$ & Chlorides & Ammonia & Nitrates & Sulphates \\
\hline 1 & Low values & - & Low values & Increased \\
2 & Low values & - & Low values & High values \\
3 & Low values & - & Increased values & Increased values \\
4 & Low values & - & Low values & Increased values \\
5 & Low values & - & Low values & Very high values \\
\hline
\end{tabular}

TABLE 3. Salinity measurement.

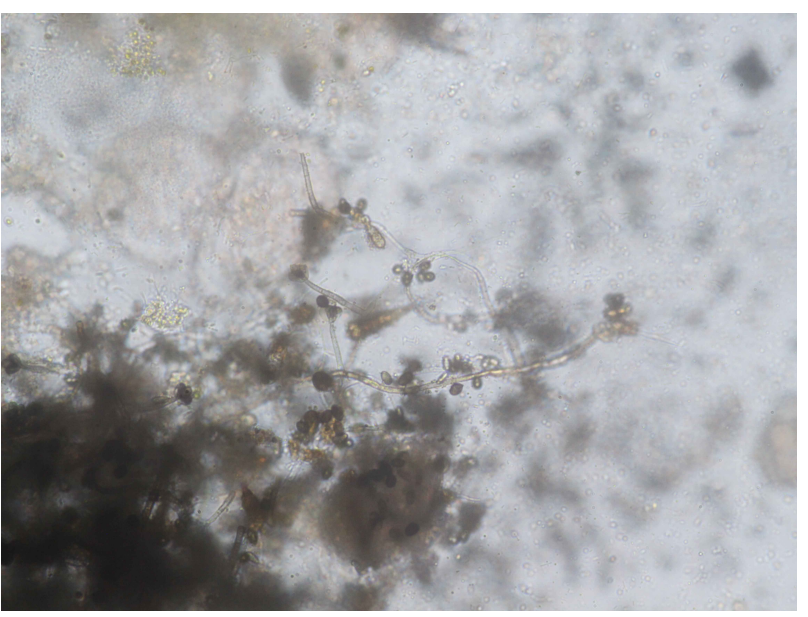

FiguRE 13. Cladosporium herbarum.

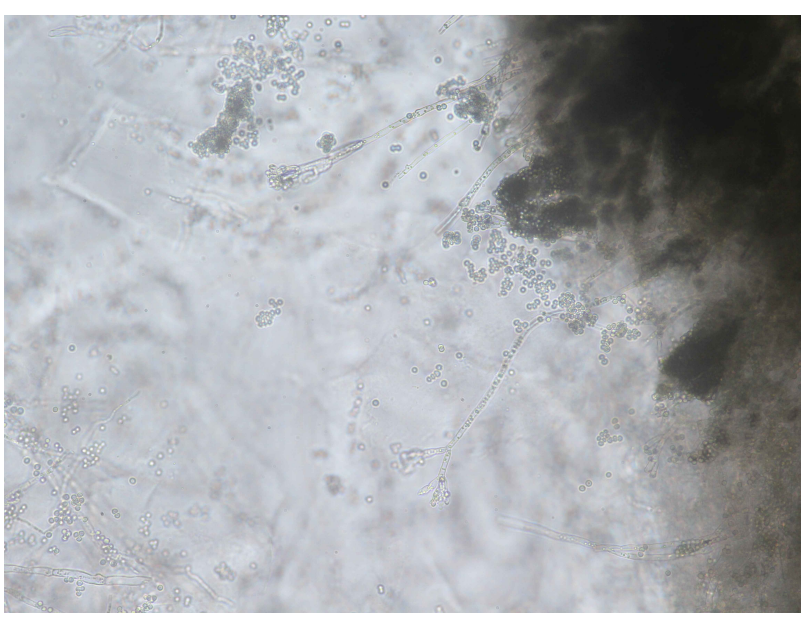

Figure 14. Penicillium.

\section{Results And Discusion}

A Spectrogant Pharo 300 UV-VIS photometer gives the result in $\mathrm{mg} / \mathrm{l}$, so it is necessary to make a conversion to $\mathrm{mg} / \mathrm{g}$. The following table reads the converted values to $\mathrm{mg} / \mathrm{g}$.

The $\mathrm{pH}$ value ranges from 8.5 to 10 , which is common with this old concrete. It can be determined that the water penetrating from the subsoil and the rainwater are not strongly acidic. Salinity sample survey shows very low levels of saturation with chlorides and nitrates. The presence of chemicals was most evident in sample number 2 (interior of the basement of heavy fortification model No. 20) and sample number 5 (the lower part of the wall in the exterior of heavy fortification model No. 20). Sulphates at this point are most likely to enter the concrete because of the lack of waterproofing is missing on the walls and floor.

Knowledge of chemical content in concrete is very important for the future design of remediation measure (such as using crystalline materials [2 4] ). Knowing the amount of sulphates is important because of the aggressiveness assessment of lime and cement mortars and plasters. It also influences the possible use of grouts of the same composition.

Another part of the experiment was to determine the presence of mold. A total of 6 common types of mold that have been found should not affect any remediation.

\section{Conclusion}

The concrete used for two analyzed Czech WW2 fortifications successfully resisted the long-lasting effects of chemical corrosion as well as bio-corrosion. The chemical corrosion causes only aesthetic defects. This conclusion applies only to mechanically preserved objects that have not been damaged by military tests (cannons shooting) or the looting of raw materials from their construction. In addition, the findings open the way for improved rehabilitation methods, which methodology is the subject of further research conducted by the authors.

\section{ACKNOWLEDGEMENTS}

This article was created with the support of the project NAKI II - DG18P02OVV063.

\section{REFERENCES}

[1] Merck KGaA. http://www.merckmillipore.com/CZ/cs, 2018. Accessed: 16 July 2018.

[2] M. J. Al-Kheetan, M. M. Rahman, D. A. Chamberlain. A novel approach of introducing crystalline protection material and curing agent in fresh concrete for enhancing hydrophobicity. Construction and Building Materials 160:644-652, 2018. DOI:10.1016/j.conbuildmat.2017.11.108.

[3] P. Reiterman, J. Pazderka. Crystalline coating and its influence on the water transport in concrete. Advances in Civil Engineering 2513514, 2016. DOI:10.1155/2016/2513514 
[4] J. Pazderka, E. Hájková. Crystalline admixtures and their effect on selected properties of concrete. Acta Polytechnica 56(4):306-311, 2016.

DOI:10.14311/AP.2016.56.0306. 